\title{
SISTEM INFORMASI PEMESANAN KAMAR MESS PT. KAI PERSERO DIVRE III SUMATERA SELATAN
}

\author{
Winoto Chandra ${ }^{1}$, Rahayu Amalia ${ }^{2}$ \\ 1,21 Universitas Bina Darma \\ JL. Jenderal A. Yani No. 03 Palembang, 30264 Indonesia \\ winoto.chan@gmail.com
}

\begin{abstract}
Abstrak - PT. Kereta Api Indonesia (KAI) Persero Divre III Sumatera Selatan merupakan salah satu Badan Usaha Milik Negara (BUMN) yang memiliki mess yang dapat digunakan bagi karyawan ataupun keluarga dari karyawan PT. KAI Persero Divre III Sumatera Selatan. Saat ini, sistem pemesanan kamar mess tidak terdata dengan baik sehingga tidak jarang petugas penjaga mess salah memberikan informasi tentang kamar mess yang kosong. Oleh karena itu, pada penelitian ini dilakukan rancang bangun sistem informasi pemesanan kamar pada mess PT. KAI Persero Divre III Sumatera Selatan mengunakan metode action research. Sistem informasi pemesanan kamar mess ini berbasis web dan di rancang bangun menggunakan bahasa pemrograman PHP, dimana pada sistem ini akan di-input data kamar mess, data pengunjung hingga data pemesanan kamar mess PT. KAI Persero Divre III Sumatera Selatan. Selain itu, pada sistem informasi pemesanan kamar mess ini akan ditampilkan juga laporan dpemesanan kamar mess setiap hari hingga setiap bulannya.
\end{abstract}

Kata Kunci - Sistem Informasi, Pemesanan Kamar, Action Research, Web, PHP.

\section{PENDAHULUAN}

PT. Kereta Api Indonesia (KAI) Persero Divre III Sumatera Selatan merupakan salah satu Badan Usaha Milik Negara (BUMN) yang bergerak di bidang transportasi, dimana berupa kereta api pengangkut penumpang dan barang. PT. KAI Persero Divre III Sumatera Selatan ini memiliki mess yang berlokasi di Kota Palembang. Permasalahan yang terjadi saat ini adalah sistem pemesanan kamar mess PT. KAI Persero Divre III Sumatera Selatan yang terdata dengan rapi, sehingga petugas sering salah memberikan informasi kamar-kamar mess mana saja yang kosong kepada pengunjung. Walaupun kamar mess hanya diperuntukan karyawan serta keluarga karyawan PT. KAI Persero Divre III Sumatera Selatan, tetapi tetap saja pengunjungnya sangat banyak dan membutuhkan sistem pendataan pemesanan kamar mess hingga pelaporan pemesanan kamar mess dengan baik dan tepat. Oleh karena itu, pada penelitian dilakukan pengembangan teknologi informasi dengan menggunakan metode penelitian action research. Dengan adanya pengembangan teknologi informasi, maka aliran informasi menjadi lebih cepat, akurat dan dapat dipercaya [1]. Sehingga, pada penelitian ini dilakukan rancang bangun sistem informasi pemesanan kamar mess berbasis web menggunakan bahasa pemrograman PHP pada PT. KAI Persero Divre III Sumatera Selatan. Pada penelitian ini dipilihlah sistem informasi berbasis web dikarenakan web dapat memberikan tampilan atau interface yang menarik. Mulai dari segi penataan informasi yang akan ditampilkan, tampilan menu, kejelasan informasi, pemilihan ataupun kombinasi warna yang digunakan serta kejelasan dari bentuk huruf (font) yang digunakan [2].

\section{TINJAUAN PUSTAKA}

\section{A. Sistem Informasi}

Sistem Informasi terdiri dari dua kata, yaitu "sistem" dan "informasi". Sistem merupakan suatu jaringan kerja dari prosedur-prosedur yang saling berhubungan, berkumpul bersama-sama untuk melakukan kegiatan atau tujuan tertentu [3], serta informasi adalah adalah data yang telah diolah menjadi bentuk yang lebih berguna bagi yang menerima [4]. Oleh karena itu, sistem informasi dapat diartikan sebagai kumpulan elemen-elemen yang saling berhubungan satu sama lain dan membentuk satu kesatuan yang apabila dieksekusi akan menyediakan informasi untuk mendukung pengambil keputusan [5].

\section{B. Bahasa Pemrograman PHP}

PHP adalah singkatan dari PHP Hypertext Preprocessor, bahasa interpreter yang mempunyai kesamaan dengan bahasa $\mathrm{C}$ dan Perl yang memiliki kesederhanaan dalam perintah serta digunakan dalam pembuatan aplikasi web [6]. Bahasa Pemrograman PHP adalah bahasa server-side scripting yang menyatu dengan HTML untuk membuat halaman web dinamis, dimana server-side scripting merupakan sintaks dan instruksi-instruksi yang diberikan sepenuhnya akan diproses pada server tetapi disertakan pada dokumen HTML [7]. PHP merupakan bahasa pemrograman script yang sangat sering digunakan saat ini, dimana PHP banyak digunakan untuk membangun web dinamis serta tidak menutup kemungkinan digunakan untuk pemakaian lainnya [8]. PHP yang merupakan bahasa pemrograman web juga dapat digunakan untuk 
melakukan HTTP (Hypertext Transfer Protocol) Request [9]. Bahasa pemrograman PHP juga dapat dipergunakan dalam mengakses berbagai jenis database, seperti Access, Oracle, MySQL dan lainnya [10]. Selain itu, bahasa pemrograman PHP juga mengembangkan fungsi Responsive web dimana tampilan layout web dapat menyesuaikan dengan ukuran viewport dari perangkat yang digunakan seperti smartphone, tablet ataupun computer screen [11].

C. $M y S Q L$

MySQL adalah suatu software relasi basis data (Relational Database Management System atau DBMS), seperti halnya Oracle, PostgreSQL, MsSQL dan lainnya. SQL (Structure Query Language) ialah suatu sintaks perintah-perintah tertentu atau bahasa program yang digunakan untuk mengelola suatu database, sehingga dapat dijelaskan bahwa $M y S Q L$ merupakan software-nya dan SQL adalah bahasa perintahnya [12]. MySQL merupakan database server yang berhubungan erat dengan pemrograman, dimana MySQL bersifat terbuka atau open source [13]. Untuk dapat memproses database MySQL maka diperlukan program XAMPP yang merupakan salah satu paket instalasi apache, PHP dan MySQL secara instant serta dapat dipergunakan untuk membantu proses instalasi ketiga produk tersebut [14].

\section{METODE PENELITIAN}

Bagian perancangan sistem menguraikan bagaimana alur proses input dan output dari sistem yang akan dihasilkan. Perancangan sistem ini dapat digambarkan melalui diagram aliran data maupun konteks diagram yang akan menggambarkan aliran data terhadap sistem yang dirancang.

Penelitian ini menggunakan metode action research, dimana metode ini merupakan bentuk rancangan peneitian yang menjabarkan, menginterpretasi serta memberikan penjelasan tentang kondisi sosial pada saat yang bersamaan dengan cara melakukan perubahan untuk tujuan perbaikan dan pengembangan [15]. Metode ini memiliki lima tahapan, yaitu Diagnosing, Action Planning, Action Taking, Evaluating dan Learning seperti pada gambar di bawah ini [16]:

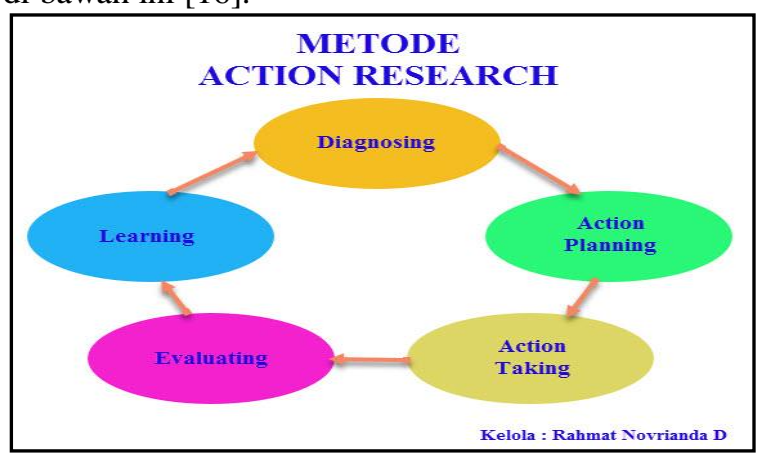

Gbr. 1 Metode Action Research

\section{A. Diagnosing}

Pada tahapan ini, dilakukan observasi, identifikasi serta analisa terhadap permasalah yang terjadi pada sistem informasi pemesanan kamar mess pada PT. KAI Persero Divre III Sumatera Selatan.

\section{B. Action Planning}

Tahapan ini merupakan tahapan dimana peneliti melakukan perencanaan akan tindakan yang dapat dilakukan untuk memberikan solusi terhadap permasalahan yang telah dianalisa pada tahapan sebelumnya, dimana peneliti merencanakan untuk membangun sistem informasi pemesanan kamar mess berbasis web.

\section{Action Taking}

Pengambilan tindakan untuk pemberian solusi terhadap permasalahan yang terjadi pada penelitian ini adalah dengan melakukan rancang bangun sistem informasi pemesanan kamar mess berbasis web dengan menggunakan bahasa pemrograman PHP serta $M y S Q L$ sebagai database-nya.

\section{Evaluating}

Pada tahapan ini dilakukan evaluasi ataupun penilaian terhadap sistem informasi pemesanan kamar mess PT. KAI Persero Divre III Sumatera Selatan yang telah dibangun. Baik dari segi manfaat, fungsi hingga penerapannya.

\section{E. Learning}

Tahapan ini merupakan tahapan terakhir dalam metode action research, dimana pembelajaran dilakukan berdasarkan tahapan evaluating yang telah dilakukan sebelumnya. Pembelajaran (Learning) yang dilakukan pada tahapan ini baik bertujuan untuk perbaikan maupun pengembangan sistem informasi pemesanan kamar mess PT. KAI Persero Divre III Sumatera Selatan.

\section{HASIL DAN PEMBAHASAN}

\section{A. Desain Sistem}

Desain sistem pada penelitian ini menggunakan Unifed Modelling Language (UML) merupakan suatu alat untuk memvisualisasikan dan mendokumentasikan hasil analisa dan desain yang berisi sintak dalam memodelkan sistem secara visual [17]. Alat bantu yang digunakan dalam perancangan berorientasi objek berbasiskan UML yaitu Use Case Diagram, Activity Diagram dan Class Diagram [18], seperti berikut ini: 


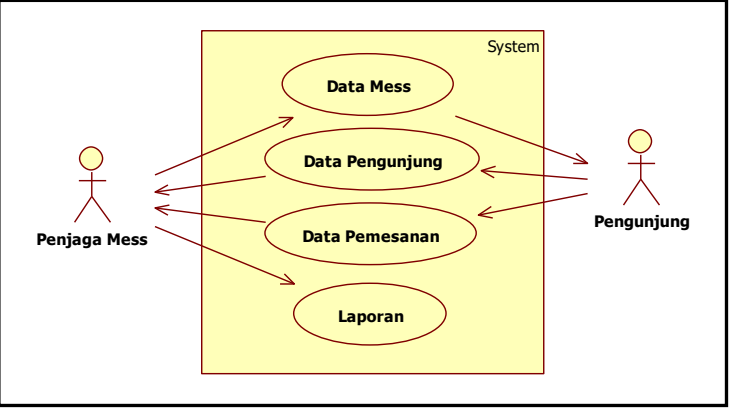

Gbr. 2 Use Case Digram

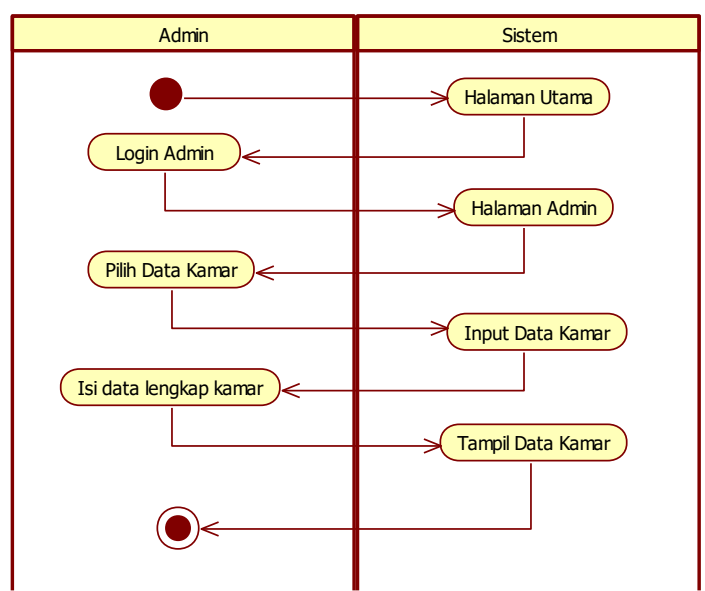

Gbr. 3 Activity Diagram Data Kamar

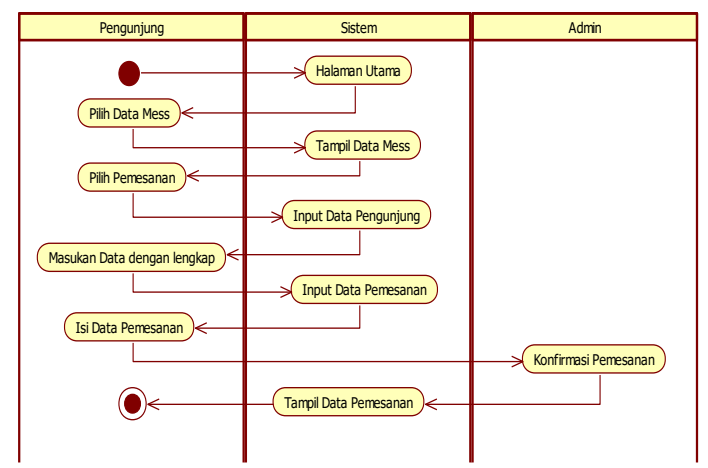

Gbr. 4 Activity Diagram Data Pemesanan

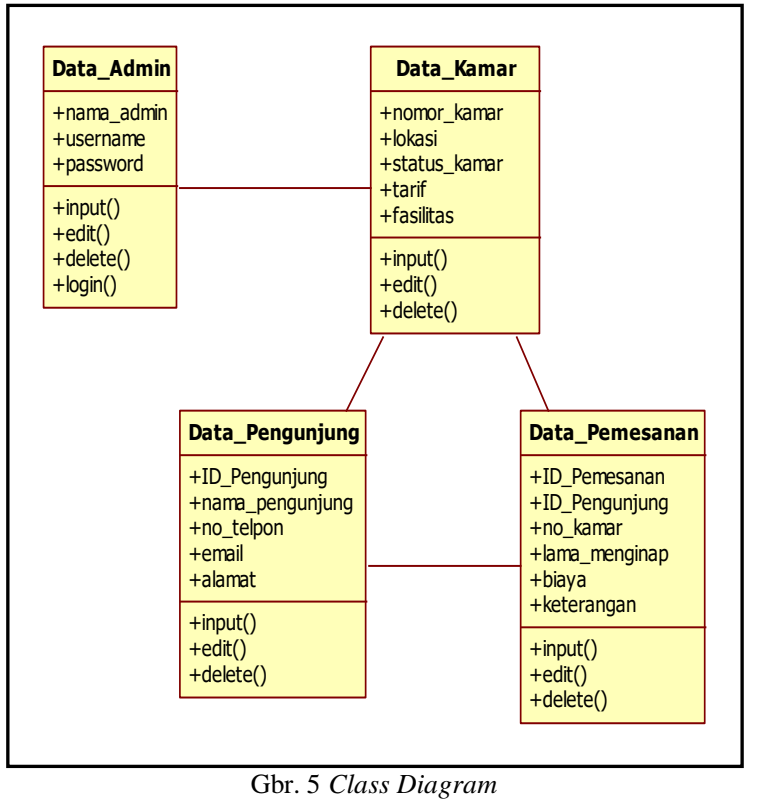

\section{B. Hasil User Interface}

Berikut ini merupakan hasil dari user interface sistem informasi pemesanan kamar mess PT. KAI Persero Divre III Sumatera Selatan menggunakan bahasa pemrograman PHP:

1. Halaman Home

Halaman ini merupakan halaman utama saat membuka sistem informasi pemesanan kamar mess PT. KAI Persero Divre III Sumatera Selatan.

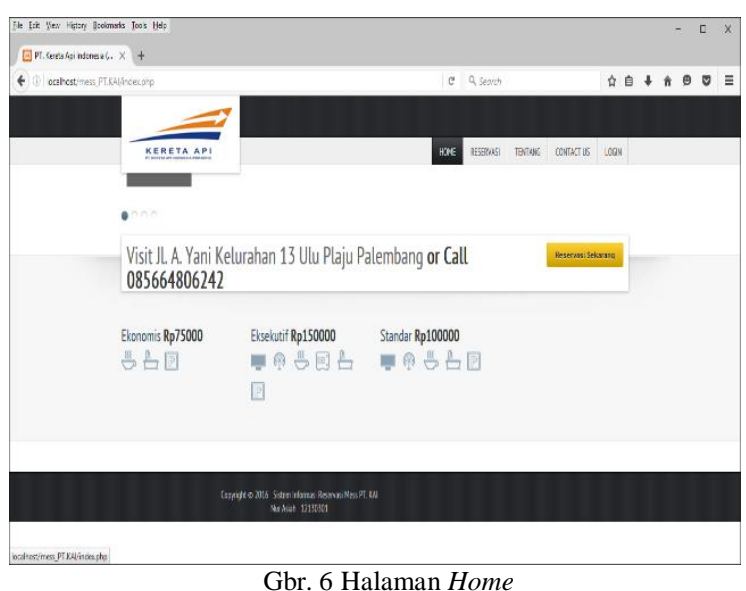

2. Halaman Pemesanan Kamar Mess

Pada halaman inilah dilakukan pemesanan kamar mess oleh pengunjung dan secara otomatis akan terdetesi kamar-kamar mess mana saja yang telah terisi. 


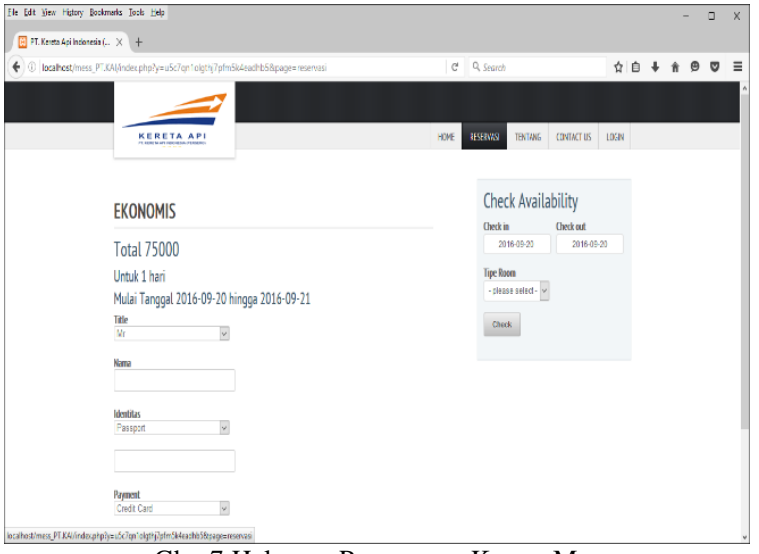

Gbr. 7 Halaman Pemesanan Kamar Mess

\section{Halaman About}

Pada halaman ini dijelaskan sejarah PT. KAI Persero Divre III Sumatera Selatan secara singkat untuk mengenal perusahaan tersebut.

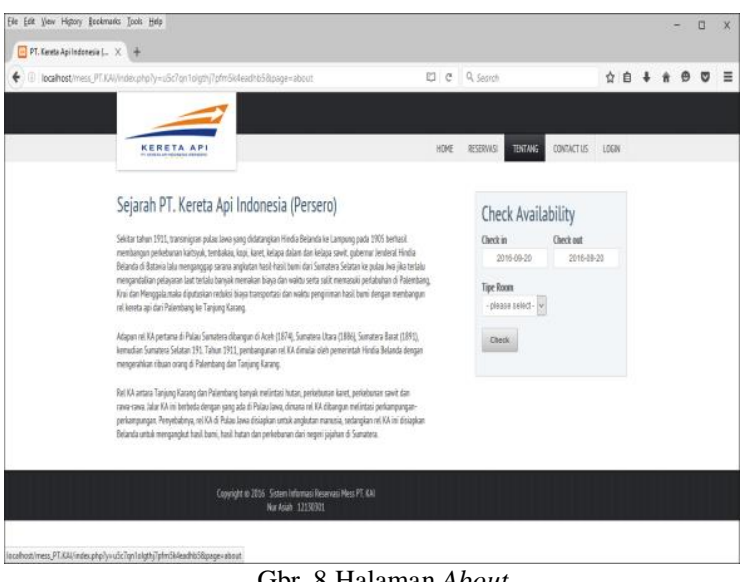

\section{Halaman Contact Us}

Halaman Contact Us merupakan halaman yang terdapat no telpon pihak pengelola mess PT. KAI Persero Divre III Sumatera Selatan yang dapat dihubungi.

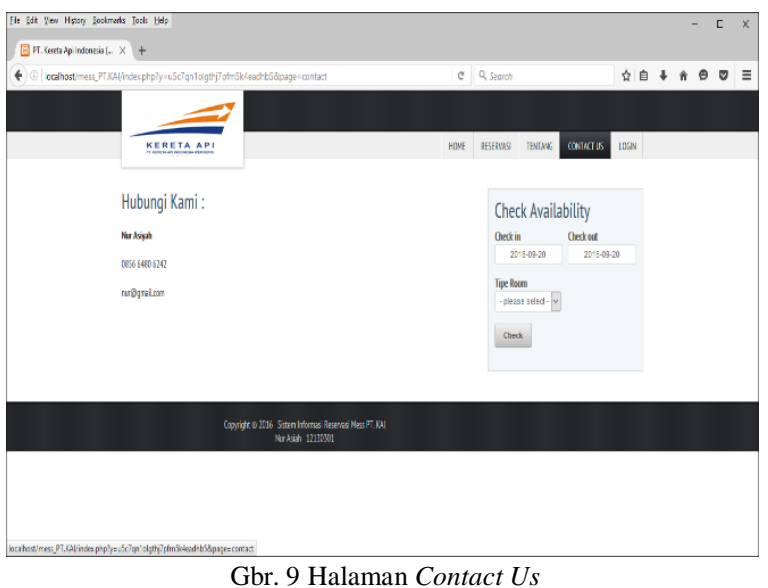

Gbr. 9 Halaman Contact Us

\section{Halaman Login Admin}

Halaman ini dipergunakan admin untuk memasukan username dan password agar dapat masuk ke halaman admin untuk pengelolaan sistem informasi pemesanan kamar mess PT. KAI Divre III Sumatera Selatan.

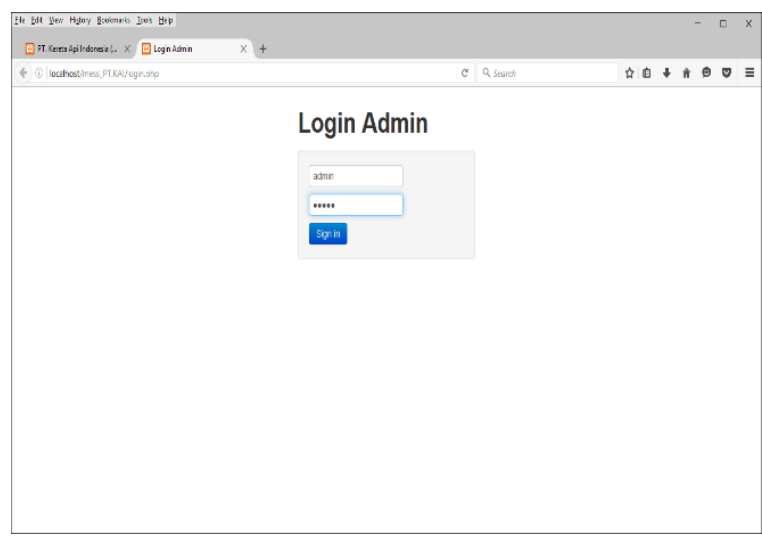

Gbr. 10 Halaman Login Admin

6. Halaman Admin

Setelah admin melakukan login, maka halaman admin yang pertama kalian muncul dapat dilihat pada gambar 11 di bawah ini:

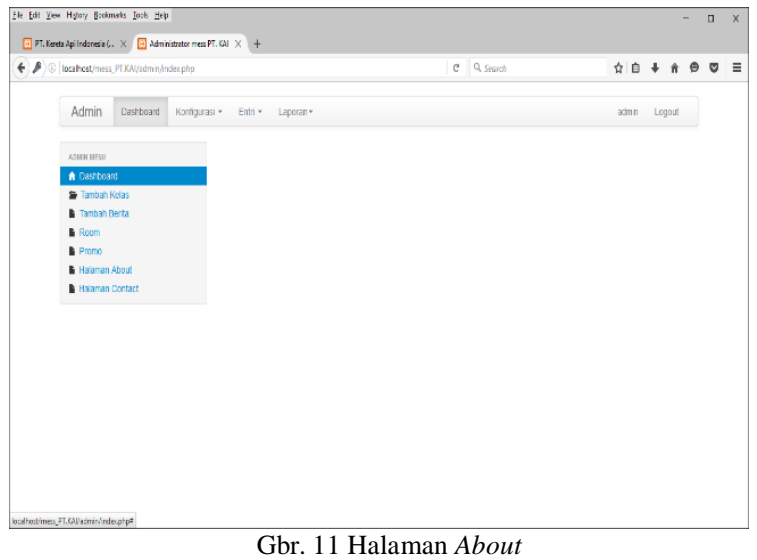

7. Halaman Input Tipe Kamar Mess

Halaman ini digunakan untuk menambahkan ataupun mengubah fasilitas dari tipe kamar mess PT. KAI Persero Divre III Sumatera Selatan.

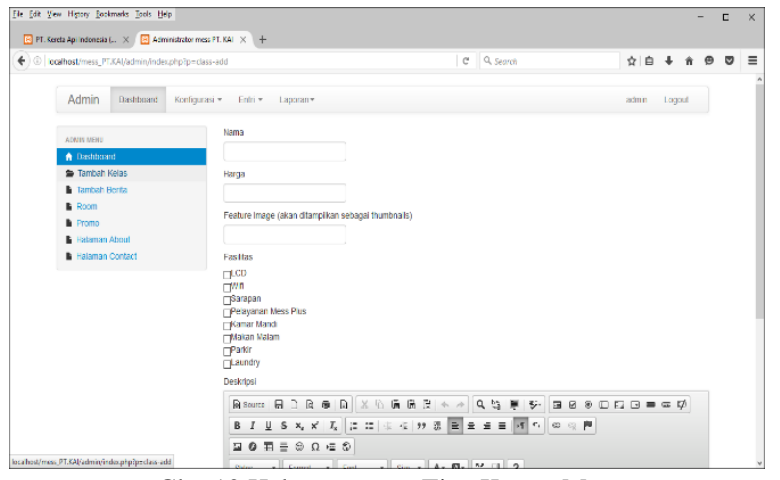

Gbr. 12 Halaman Input Tipe Kamar Mess 
8. Halaman Input Kamar Mess

Pada halaman ini, dapat dilakukan penambahan kamar mess baru ataupun pengubahan data kamar mess yang ada saat ini.

Page | 92

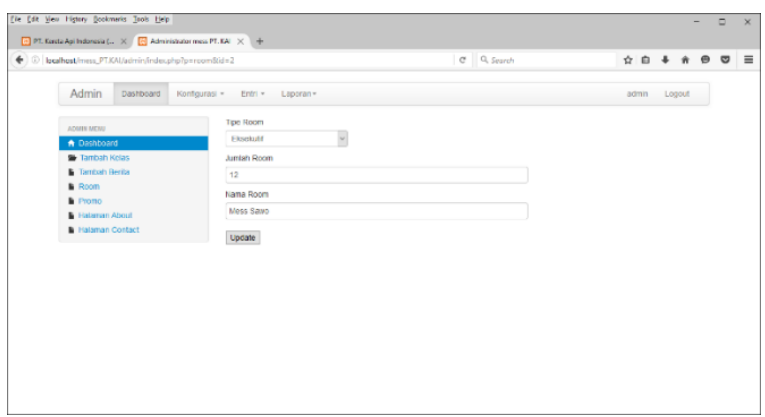

Gbr. 13 Halaman Input Kamar Mess

9. Laporan Pemesanan Kamar Mess

Hasil dari seluruh pemesanan kamar mess pada sistem informasi yang telah dibangun dapat direkap dan ditampilkan pada halaman yang terlihat pada gambar 14 di bawah ini dalam bentuk file PDF.

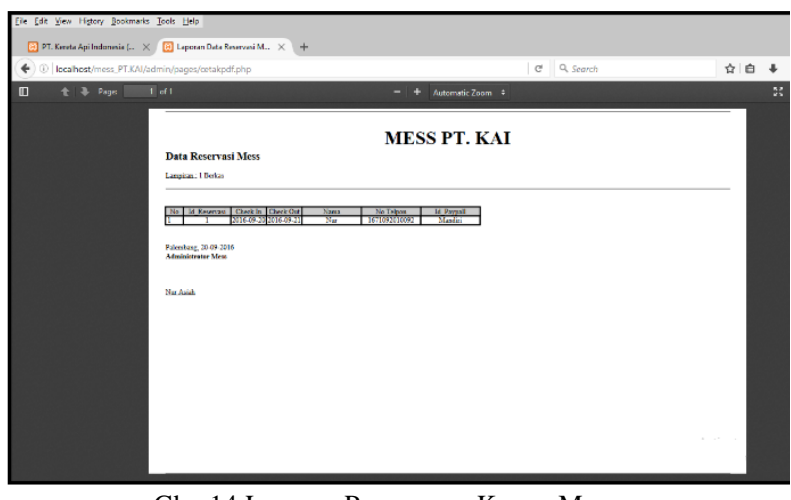

Gbr. 14 Laporan Pemesanan Kamar Mess

\section{Pembahasan}

Pada penelitian ini dihasilkan sistem informasi pemesanan kamar mess pada PT. KAI Persero Divre III Sumatera Selatan menggunakan bahasa pemrograman PHP. Pada sistem informasi ini, dapat dilakukan input data kamar mess beserta fasilitas-fasilitasnya serta pada sistem informasi ini juga dapat di-input data pemesanan dengan output laporan pemesanan kamar mess PT. KAI Persero Divre III Sumatera Selatan. Oleh karena itu, sistem informasi ini menjadi solusi terhadap permasalahan pendataan pemesanan kamar mess yang saat ini terjadi pada PT. KAI Persero Divre III Sumatera Selatan.

\section{PENUTUP}

Dari hasil penelitian yang telah dilakukan, dapat disimpulkan bahwa bahasa pemrograman dengan tambahan database $M y S Q L$ dapat digunakan untuk rancang bangun sistem pemesanan kamar mess pada PT. KAI Persero Divre III Sumatera Selatan dengan tampilan yang menarik dan dinamis. Selain itu, sistem informasi yang telah dibangun pada penelitian ini mudah digunakan oleh operator khususnya penjaga mess serta memudahkan pengunjung dalam melakukan pengecekan kamar kosong serta melakukan pemesanan kamar mess sesuai dengan kebutuhan pengunjung.

\section{UCAPAN TERIMAKASIH}

Terima kasih disampaikan kepada segenap staf PT. KAI Persero Divre III Sumatera Selatan, terutama staf pada mess PT. KAI Persero Divre III Sumatera Selatan yang berada di Kota Palembang.

\section{REFERENSI}

[1] R. Priskila, "Perancangan Sistem Informasi Persediaan Barang pada Perusahaan Karya Cipta Buana Sentosa berbasis web dengan Metode Extreme Programing," CESS (Journal Comput. Eng. Syst. Scence), vol. 3, no. 2, pp. 94-99, 2018

[2] M. S. Putra, "Faktor-Faktor Pengembangan Sistem Informasi Akademik berbasis Web pada Perguruan Tinggu Swasta Palembang," J. Resti (Rekayasa Sist. dan Teknol. Informasi), vol. 2, no. 1, pp. 295-300, 2018.

[3] J. Hutahaean, Konsep Sistem Informasi, 1st ed. Yogyakarta: Deepublish, 2015.

[4] H. T. Sitohang, "Sistem Informasi Pengagendaan Surat berbasis Web Pada Pengadilan Tinggi Medan," J. Inform. Pelita Nusant., vol. 3, no. 1, pp. 6-9, 2018.

[5] D. Darmastuti, "Implementasi Metode Simple Additive Weighting (SAW) dalam Sistem Informasi Lowongan Kerja berbasis Web untuk Rekomendasi Pencari Kerja Terbaik," $J$. Sist. dan Teknol. Inf., vol. 1, no. 2, pp. 114-119, 2013.

[6] S. K. Wardani, "Sistem Informasi Pengolahan Data Nilai Siswa berbasis Web pada Sekolah Menengah Atas (SMA) Muhammadiyah Pacitan," IJNS (Indonesian J. Netw. Secur., vol. 2, no. 2, pp. 30-37, 2013.

[7] D. E. Hendrianto, "Pembuatan Sistem Informasi Perpustakaan berbasis Website pada Sekolah Menengah Pertama Negeri 1 Donorojo Kabupaten Pacitan," IJNS (Indonesian J. Netw. Secur., vol. 3, no. 4, pp. 57-64, 2014.

[8] S. Ramadhani, U. Anis, and S. T. Masruro, "Rancang Bangun Sistem Informasi Geografis Layanan Kesehatan di Kecamatan Lamongan dengan PHP MySQL," J. Tek., vol. 5, no. 2, pp. 479-483, 2013.

[9] M. R. S. Surendra, "Implementasi PHP Web Service sebagai Penyedia Data Aplikasi Mobile," ULTIMATICS, vol. 6, no. 2, pp. 85-93, 2014.

[10] U. Hasanah, "Sistem Informasi Penjualan On_Line pada Toko Kreatif Suncom Pacitan," IJNS (Indonesian J. Netw. Secur., vol. 2, no. 4, pp. 40-48, 2013.

[11] I. Solikin, "Implementasi E-Modul pada Program Studi Manajemen Informatika Universitas Bina Darma berbasis Web Mobile," J. Resti (Rekayasa Sist. dan Teknol. Informasi), vol. 2, no. 2, pp. 492-497, 2018.

[12] H. Hidayat, Hartono, and Sukiman, "Pengembangan Learning Management System (LMS) untuk Bahasa Pemrograman PHP," J. Ilm. Core IT Community Res. Inf. Technol., vol. 5, no. 1, pp. 20-29, 2017.

[13] M. I. Alfarisyi, Rispianda, and K. Amila, "Rancangan Sistem Informasi Layanan Alumni Itenas berbasis Web," Reka Integr., vol. 1, no. 2, pp. 132-143, 2014. 
[14] A. Prayitno and Y. Safitri, "Pemanfaatan Sistem Informasi Perpustakaan Digital berbasis Website untuk Para Penulis," IJSE (Indonesian J. Softw. Eng., vol. 1, no. 1, pp. 1-10, 2015.

[15] R. Novrianda.D, "Implementasi Metode VLSM (Variable Length Subnet Mask) pada Pemetaan IP Address LAN (Local Area Network) STIPER Sriwigama Palembang," Comput. J. Comput. Sci. Inf. Syst., vol. 2, no. 2, pp. 112-118, 2018.

Page $\mid 93$

[16] R. Novrianda.D and R. M. N. Halim, "Implementasi Papan Informasi Digital menggunakan Raspberry Pi 3 pada STIPER Sriwigama Palembang," Comput. J. Comput. Sci. Inf. Syst., vol. 2, no. 2, pp. 196-206, 2018.

[17] N. Ainun, Hartono, and Jimmy, "Perancangan Aplikasi Mobile Repository Skripsi (Skripsi Alumni Mahasiswa) STMIK IBBI Medan berbasis Android," J. Ilm. Core IT Community Res. Inf. Technol., vol. 5, no. 2, pp. 18-27, 2017.

[18] A. Hendini, "Pemodelan UML Sistem Informasi Monitoring Penjualan dan Stok Barang (Studi Kasus: Distro Zhezha Pontianak)," J. Khatulistiwa Inform., vol. 4, no. 2, pp. 107116, 2016 